\title{
Pediatric dental sedation: challenges and opportunities
}

This article was published in the following Dove Press journal:

Clinical, Cosmetic and Investigational Dentistry

26 August 2015

Number of times this article has been viewed

\section{Travis M Nelson \\ Zheng Xu}

Department of Pediatric Dentistry, University of Washington, Seattle, WA, USA
Correspondence: Travis M Nelson Department of Pediatric Dentistry, University of Washington, $6222 \mathrm{NE}$ 74th Street, Seattle, WA 98115, USA Email tmnelson@uw.edu
Abstract: High levels of dental caries, challenging child behavior, and parent expectations support a need for sedation in pediatric dentistry. This paper reviews modern developments in pediatric sedation with a focus on implementing techniques to enhance success and patient safety. In recent years, sedation for dental procedures has been implicated in a disproportionate number of cases that resulted in death or permanent neurologic damage. The youngest children and those with more complicated medical backgrounds appear to be at greatest risk. To reduce complications, practitioners and regulatory bodies have supported a renewed focus on health care quality and safety. Implementation of high fidelity simulation training and improvements in patient monitoring, including end-tidal carbon dioxide, are becoming recognized as a new standard for sedated patients in dental offices and health care facilities. Safe and appropriate case selection and appropriate dosing for overweight children is also paramount. Oral sedation has been the mainstay of pediatric dental sedation; however, today practitioners are administering modern drugs in new ways with high levels of success. Employing contemporary transmucosal administration devices increases patient acceptance and sedation predictability. While recently there have been many positive developments in sedation technology, it is now thought that medications used in sedation and anesthesia may have adverse effects on the developing brain. The evidence for this is not definitive, but we suggest that practitioners recognize this developing area and counsel patients accordingly. Finally, there is a clear trend of increased use of ambulatory anesthesia services for pediatric dentistry. Today, parents and practitioners have become accustomed to children receiving general anesthesia in the outpatient setting. As a result of these changes, it is possible that dental providers will abandon the practice of personally administering large amounts of sedation to patients, and focus instead on careful case selection for lighter in-office sedation techniques.

Keywords: conscious sedation, anesthesia, general, pediatrics

\section{Introduction}

The developing child often lacks the coping skills necessary to navigate the dental experience, making provision of quality dental care to children challenging. While unrestored caries may contribute to pain, disordered sleep, difficulty learning, and poor growth in children, unpleasant dental experiences can cause psychologic harm. ${ }^{1-3}$ Most dental anxiety develops in childhood as a result of frightening and painful dental experiences. If appropriate precautions are not taken, dental treatment may overwhelm the child, resulting in dental fear and avoidance. ${ }^{4}$ These fears persist into adulthood, causing $10 \%-20 \%$ of the US population to avoid necessary dental care. ${ }^{5,6}$ Sedation reduces such complications and instills trust in the family and child. 
Today, it is estimated that $100,000-250,000$ pediatric dental sedations are performed each year in the USA, and practitioners anticipate a need for more pharmacologic behavior management in the future. ${ }^{7,8}$ High levels of pediatric dental disease, increasingly difficult child behavior, and parent expectations support a need for sedation services. ${ }^{8-11}$ Here we review common challenges that contemporary dental practitioners experience and suggest possible solutions.

\section{Risk factors for adverse events}

Sedation is a continuum. Physiologic effects vary significantly depending upon a variety of factors, including medication, dose, delivery route, and patient characteristics. ${ }^{12,13}$ Minimal sedation is considered to be the mildest form of sedation. As stronger medications and higher doses are administered, the depth of sedation shifts toward moderate sedation, deep sedation, and possibly even general anesthesia. At more profound levels, patients become unresponsive and incapable of maintaining their own breathing or cardiovascular function. ${ }^{14,15}$ In adult dental practice, titration of sedation depth through intravenous drug administration is common. In pediatrics, however, due to behavioral constraints, sedation by bolus oral administration is well tolerated and routine. ${ }^{7,13}$ With oral administration, sedation depth can be difficult to predict and titration is not possible. ${ }^{16}$ Consequently, oversedation and respiratory obstruction can occur. Should this happen, it is the responsibility of the sedation provider to manage the unconscious child until she or he regains the ability to self-regulate.

Sedation for dental procedures has been implicated in a disproportionate number of cases that resulted in death or permanent neurologic damage. ${ }^{17-19}$ When causes of sedation-related injury and death in outpatient settings have been reviewed, damage almost always resulted from an inability to resuscitate once a patient lost protective reflexes. ${ }^{17,18,20,21}$ Children under 5 years of age and those with pre-existing medical conditions appear to be at greatest risk. ${ }^{17,18,21}$ These findings have led to increased scrutiny of pediatric dental sedation by the public and the medical community. ${ }^{20,22}$ One concern is that dentists and other non-anesthesiologist practitioners receive varying levels of sedation training and often do not practice in settings with immediate access to rescue resources such as a code team. In contrast, anesthesiologists receive relatively uniform training and practice the skills required to rescue patients on a daily basis. They also commonly practice in an operating room environment and have the ability to request backup when needed.

\section{Patient monitoring}

Early efforts to provide sedation in the dental office were largely unregulated, and clinicians primarily relied only on direct physical findings such as quality of respiration and patient color to assess the sedated patient. Over time technology improved, and professional associations and regulatory bodies provided a framework for safe and effective practice. ${ }^{16,23,24}$ Advancements included monitoring patients with blood pressure monitors and precordial stethoscopes. With the advent of pulse oximetry, electronic monitoring of blood oxygen saturation further increased safety. This allowed for continuous monitoring of heart rate and blood oxygen saturation, with alarm activation when blood pressure or oxygenation declined below a threshold value. In contemporary practice, end-tidal carbon dioxide $\left(\mathrm{E}_{\mathrm{t}} \mathrm{CO}_{2}\right)$ monitors have become standard in operating rooms to monitor apnea and hypoventilation.

In response to growing safety concerns, $\mathrm{E}_{\mathrm{t}} \mathrm{CO}_{2}$ monitoring is now used increasingly in ambulatory settings ${ }^{17,18,20,25}$ (Figure 1). Professional association guidelines reflect this trend, and the American Society of Anesthesiologists has amended its standards for basic anesthetic monitoring to require $\mathrm{E}_{\mathrm{t}} \mathrm{CO}_{2}$ for moderate or deep sedation. ${ }^{25}$ In dentistry, perhaps the most widely recognized professional sedation guidelines come from the American Dental Association. For children 12 years of age and under, the American Dental Association recognizes the American Academy of Pediatrics/ American Academy of Pediatric Dentistry (AAP/AAPD) guidelines for monitoring and management of pediatric patients during and after sedation for diagnostic and therapeutic procedures. Both the American Dental Association and the AAP/AAPD guidelines suggest that $\mathrm{E}_{\mathrm{t}} \mathrm{CO}_{2}$ monitoring may

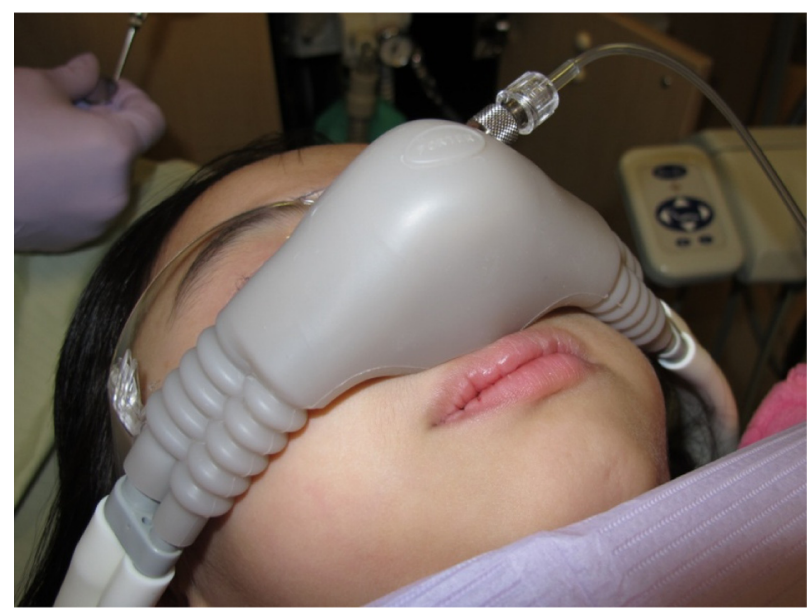

Figure I Nitrous oxide nasal hood modified for use with an end-tidal carbon dioxide sampling line. 
be used to evaluate respiration; however, it is not currently required for moderate sedation. ${ }^{16,26}$ In the USA, each state has unique requirements for a dentist to perform sedation. States vary considerably regarding training standards, required continuing education, and advanced life support credentials required to maintain a sedation permit. ${ }^{27}$ Similarly, there is no nationally recognized government standard for monitoring of dental patients during sedated procedures. However, some states have begun to mandate the use of $\mathrm{E}_{\mathrm{t}} \mathrm{CO}_{2}$ monitors for dental sedation. Given this trend, it is possible that in the future $\mathrm{E}_{\mathrm{t}} \mathrm{CO}_{2}$ monitoring will become the standard for sedated patients in dental offices and health care facilities.

\section{Modern drugs and routes}

Selection of medications is a critical component of the sedation plan. When possible, consideration should be given to sedatives with available reversal agents. In the event of oversedation, benzodiazepine and narcotic medications may be preferred over drugs without known reversal agents, such as chloral hydrate. In recent years, both the solution and capsule form of chloral hydrate have been withdrawn from the US market. In the future, in spite of its historic success, chloral hydrate will likely continue to fall out of favor for pediatric dental sedation.

Oral sedation is the most popular route of administration among pediatric dentists. ${ }^{28,29}$ However, this route is notoriously unpredictable, and frustration often arises when children refuse to accept the sedative medication. ${ }^{28,30}$ Efforts have been made to mask the bitter taste of the oral medications; however, it is not uncommon for children to spit or regurgitate them. On the other hand, placement of an intravenous cannula for parenteral sedation can be traumatic to children. ${ }^{30}$ New methods of medication delivery have been proposed and investigated. One alternative is the transmucosal (intranasal, sublingual, buccal) route. The benefits of this route include direct absorption of drugs into the systemic circulation, avoidance of hepatic first pass metabolism, increased bioavailability, and faster onset compared with oral sedation. Transmucosal administration also results in less discomfort than intravenous sedation and better acceptance by patients. ${ }^{28}$

Intranasal administration of midazolam has been proven to be a safe and effective sedative for short procedures and is widely used by pediatric dentists. ${ }^{29-36}$ In addition to quick onset, a relatively quick recovery has also been suggested. ${ }^{34}$ Some believe that another possible advantage of intranasal sedation is that a strict adherence to fasting requirements may not be essential. ${ }^{28,32,37}$ This is a controversial area; however, results of clinical trials suggest that children may be given intranasal midazolam with less risk of nausea, vomiting, and respiratory complications. ${ }^{32,37}$ While practitioners should be cautious in relaxing recognized safety standards, given the appropriate setting (such as a hospital emergency room), this technique may prove useful for uncooperative children who need emergency treatment and have eaten.

Although intranasal administration is usually simple, relatively painless, and requires less patient cooperation, it has been associated with mucosal irritation. This may lead to coughing, sneezing, crying and the expulsion of part of the dose. This is particularly true when a large volume of the drug is applied. ${ }^{34,36}$ Therefore, careful administration is critical. When administration of intranasal midazolam by drop and aerosolized form were compared, aerosolization was better tolerated and led to less aversive behavior ${ }^{29}$ (Figure 2).

Nasal mucosal secretions can also affect intranasal drug absorption. The buccal mucosa has a rich blood supply and is relatively permeable, yielding pharmacokinetics that are similar to intranasal administration. It therefore appears to be an attractive alternative to the intranasal route. ${ }^{38}$ Buccal administration of aerosolized midazolam has been proven to be safe, effective, and well accepted by young patients. ${ }^{28,39,40}$ An oral solution may also be used in place of aerosol spray; however, the possibility of experiencing the bitter taste increases, leading to poor patient acceptance. ${ }^{40}$ Buccal and intranasal midazolam have the same maximum working time while intranasal has a faster onset time. Intranasal midazolam also elicited less crying and produced a greater proportion of patients with optimal sedation scores. ${ }^{41}$ Chopra et al and

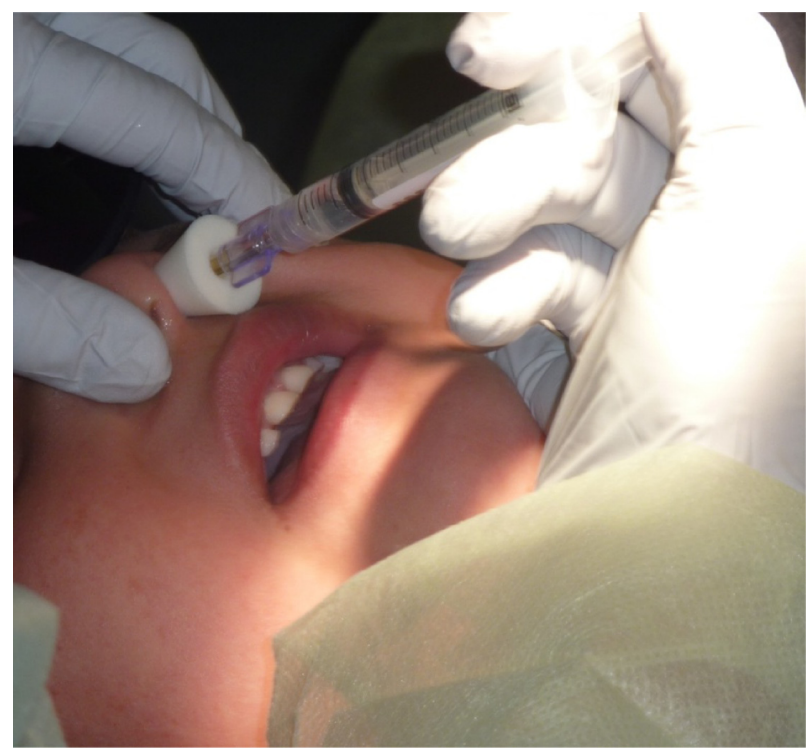

Figure 2 Child receiving intranasal midazolam using an aerosolization device. 
Klein et al reported better acceptance of the buccal route, ${ }^{28,39}$ while Sunbul et al found intranasal midazolam to be more acceptable to children. ${ }^{41}$ Interestingly, even though it was poorly tolerated by subjects during administration, in one study a greater proportion of parents preferred the intranasal route for future sedation. ${ }^{39}$

Dexmedetomidine is a selective alpha2-adrenergic agonist that provides sedative, anxiolytic, and analgesic properties without causing respiratory depression. ${ }^{42,43}$ It was approved by US Food and Drug Administration to be used for sedation in adults in the intensive care setting in 1999. Due to its efficacy in adults, in recent years it has been introduced into the pediatric population for procedural sedation outside the operating room. Dexmedetomidine is available in intranasal, buccal, or oral form. ${ }^{43}$ The safe use of dexmedetomidine in pediatric diagnostic radiology has been well documented. ${ }^{42}$ However, studies on its use for outpatient dental procedures are limited, especially in children. In a pilot study by Hitt et al, intranasal delivery of sufentanil and dexmedetomidine provided acceptable sedation without respiratory depression or major complications in 20 children undergoing dental procedures. $^{44}$

When reviewing the small clinical trials and observational studies exploring pediatric use of dexmedetomidine, it is important to note that all these studies were performed in a medically controlled setting under the supervision of anesthesiologists. ${ }^{44-46}$ Clearly, much work needs to be done to define the efficacy of dexmedetomidine and its impact on pediatric dental sedation. However, due to its unique characteristics and lack of respiratory depression, this medication holds great promise as an alternative option for sedation in the pediatric dental clinic.

\section{Optimizing care for patient safety}

Risk is inherent in procedural sedation. While it is impossible to eliminate risk entirely, negative outcomes can be minimized by optimizing work systems and eliminating human factors for error. ${ }^{47-49}$ We also reduce the chance of future incidents by recognizing accidents that were avoided but nearly occurred. These "near misses" should be reported so that contributing factors can be analyzed and eliminated. ${ }^{50}$

The greatest successes are achieved by focusing on safety before the sedation appointment. Preparation begins with appropriate case selection. Using a standard form for presedation, patient assessment helps eliminate guesswork (Figure 3). Appropriate assessment includes patient medical history, physical examination (including targeted airway assessment), and assignment of an American Society of
Anesthesiologists score. ${ }^{51,52}$ Similarly, in-office sedation should be limited to healthy children. Healthy children and those with mild systemic disease (American Society of Anesthesiologists score I and II) can generally be cared for safely and effectively in the dental clinic. Complicated medical conditions including heart disease, obstructive sleep apnea, and obesity have been shown to increase sedation risk and the chances of failed sedation. ${ }^{53}$ These factors must be considered carefully when selecting the sedation regimen and venue.

Appropriate dosing is another concern. In the USA, approximately one-third of children aged 2-19 years are overweight or obese. This represents more than a three-fold increase in childhood obesity over the past 30 years. ${ }^{54}$ In an analysis of perioperative complications, overweight and obese children had a higher incidence of difficult airway, upper airway obstruction, and longer postoperative recovery period. ${ }^{55}$ Obese children are also much more likely to have obstructive sleep apnea. ${ }^{56}$ If total body weight (TBW) is used for dose calculation, overweight children are at risk for overdose. Some authors suggest that dosing should be based upon ideal body weight (IBW) or lean body mass (LBM), although there is a lack of clear guidance in this area. ${ }^{57-59}$ Calculating IBW and LBM in children can be relatively complicated, and validity of the measurement is lost as the child grows. Simplified weight calculations for children are expressed in the following equations: ${ }^{57,59}$

$$
\begin{aligned}
& \mathrm{IBW}=\mathrm{BMI}_{50} \times \text { height }^{2} \\
& \mathrm{LBM}=\mathrm{IBW}+0.29(\mathrm{TBW}-\mathrm{IBW})
\end{aligned}
$$

Although this provides some guidance in dosing overweight children, in many circumstances calculation of appropriate dosing using this method may not be practical. It should also be remembered that when a child's actual weight is less than IBW or LBM, the lower figure should be used. An alternative nomographic method has recently been described for use in children aged 5 years and older. ${ }^{60} \mathrm{~A}$ nomograph is constructed by placing scales for known variables (ie, age, height, TBW) side by side. Known values are then plotted on each scale. The value of an unknown variable (LBM) is determined by the drawing a straight line from the points plotted on each scale. The point where the lines intersect the unknown variable scale is an approximation of its value (Figure 4). This method allows clinicians to quickly calculate LBM using a chart. One needs only to know the child's age, height, and TBW. While still an ongoing area of study, researchers anticipate development of nomographic charts 


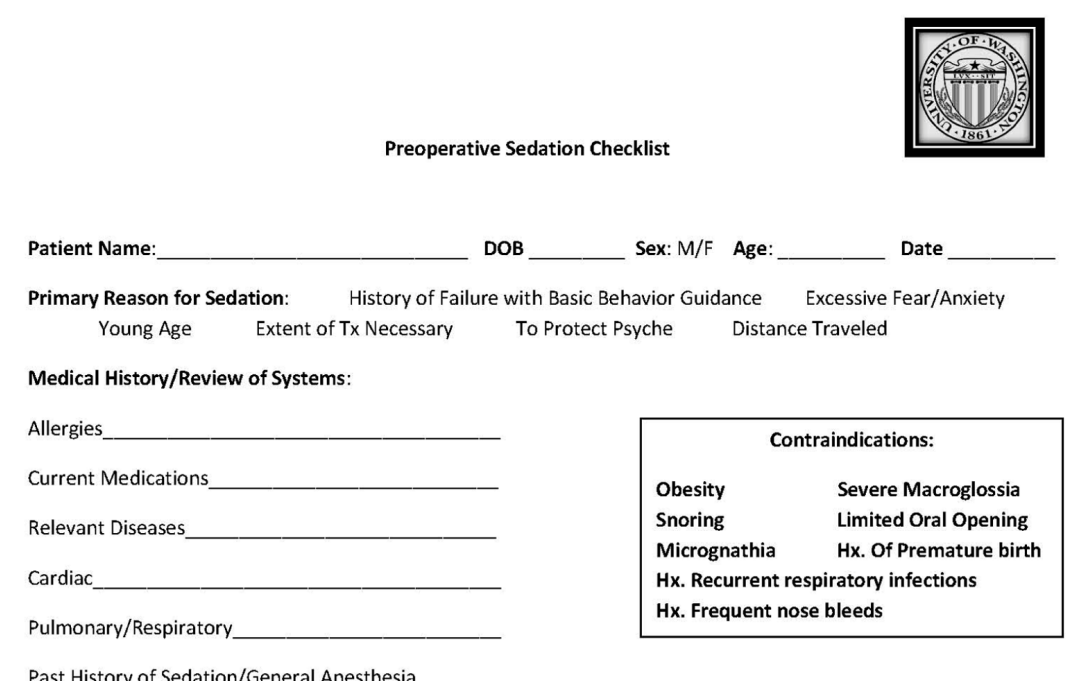

Past History of Sedation/General Anesthesia

Result of Medical Consultation (ASA I| patients)

Selection Criteria (must answer YES to all questions)

$\begin{array}{lc}\text { ASA Classification: | or I| (med consult indicated) } & \text { Yes No } \\ \text { Brodsky | or II airway } & \text { Yes No } \\ \text { Patient Age >2yrs } & \text { Yes No } \\ \text { Able to obtain radiographs (except in cases of limited treatment/extraction) } & \text { Yes No } \\ \text { Parents/Clinician believe child will swallow medications } & \text { Yes No } \\ \text { Treatment will be accomplished in 2 or fewer sedation appointments } & \text { Yes No } \\ \text { For females aged } 12 \text { and older pregnancy testing has been discussed } & \text { Yes No }\end{array}$

Is this patient a candidate for in-office sedation?

Yes No

Dentist Signature

Figure 3 A presedation checklist. ${ }^{13}$

Note: The ASA classification system is a health-grading system used commonly by medical and dental providers. ASA I = healthy, ASA II = mild systemic disease. Abbreviations: $\mathrm{Hx}$, history; Tx, treatment; M, male; F, female; ASA, American Society of Anesthesiologists.

that are validated for children under age 5 years and incorporation of the tool into a smartphone application.

Following the sedation appointment, uniform discharge criteria ensure that the child is not sent home before she or he is ready to leave direct medical supervision. A number of studies have suggested that children who are sedated for dental care routinely experience prolonged sleepiness and difficulty waking, including sleeping in the car while riding home after treatment. ${ }^{61,62}$ While tiredness can be expected following the sedation appointment, implementation of discharge criteria helps to ensure that the child is not excessively sedated when they leave the dental office. If a child is able to achieve a University of Michigan Sedation Scale score of 0 or 1 ( 0 , awake and alert or minimally sedated; 1 , tired/sleepy, appropriate response to verbal conversation and/or sound) and able to stay awake for 20 minutes when undisturbed (the Modified Maintenance of Wakefulness Test), she or he is generally considered to be ready to return home with parental supervision. ${ }^{63,64}$

Simulation training is increasingly being recognized as an important mechanism for improving health care quality and safety. Basic simulation can be as simple as regularly practicing emergency skills with office staff. Advanced simulation programs provide a means of practicing low frequency events 


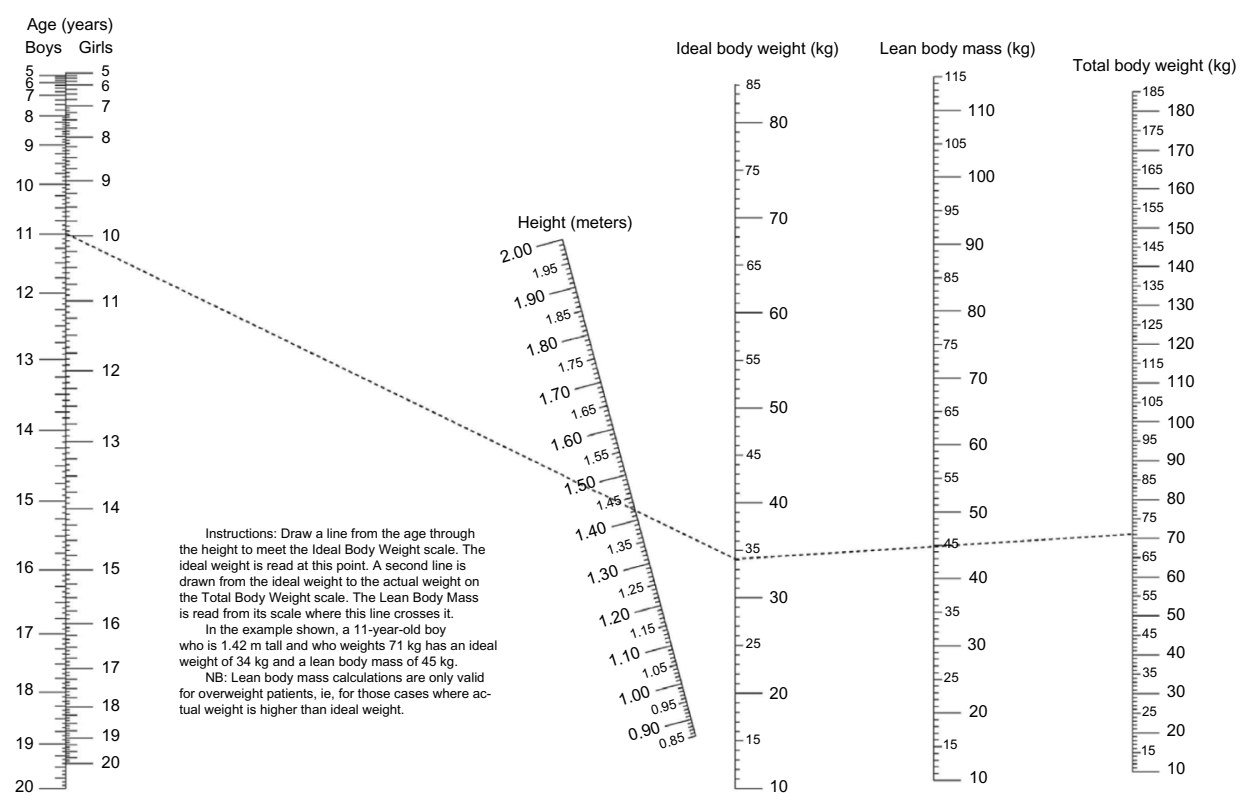

Figure $4 \mathrm{~A}$ novel body mass nomogram used for calculating lean body mass in children.

Note: Copyright $@$ C 2015. Dove Medical Press. Reproduced from Callaghan LC, Walker JD. An aid to drug dosing safety in obese children: development of a new nomogram and comparison with existing methods for estimation of ideal body weight and lean body mass. Anaesthesia. 2015;70:176-182. ${ }^{60}$

using high-fidelity clinical environments and mannequins that accurately reproduce physiologic conditions (Figure 5). When simulation is incorporated into education it increases knowledge, clinical skills, and judgment more than lectureonly teaching. ${ }^{65,66}$ Simulation is also thought to be a reliable method of teaching non-emergency sedation skills, such as presedation assessment, and it is becoming an increasingly common adjunct to sedation education programs. ${ }^{67}$

\section{Anesthesia neurotoxicity}

In recent years, it has been suggested that medications used in sedation and anesthesia may have adverse effects on the developing brain. ${ }^{68-70}$ Initial research demonstrated harm to the brains of young animals. ${ }^{71-74}$ This raised concern that young children might also be at risk when exposed to anesthetic agents. ${ }^{75}$ Following the publication of these concerning findings, human studies were initiated. ${ }^{76-79}$ The results have often revealed conflicting conclusions, with some showing long-term deficits in learning and behavior while others have not. ${ }^{80}$ This is a difficult area of study, because children who receive sedation and anesthesia commonly have pathologic conditions for which they require surgery. They may therefore be fundamentally distinct from their healthy peers. Adverse neurologic outcomes are also difficult to recognize

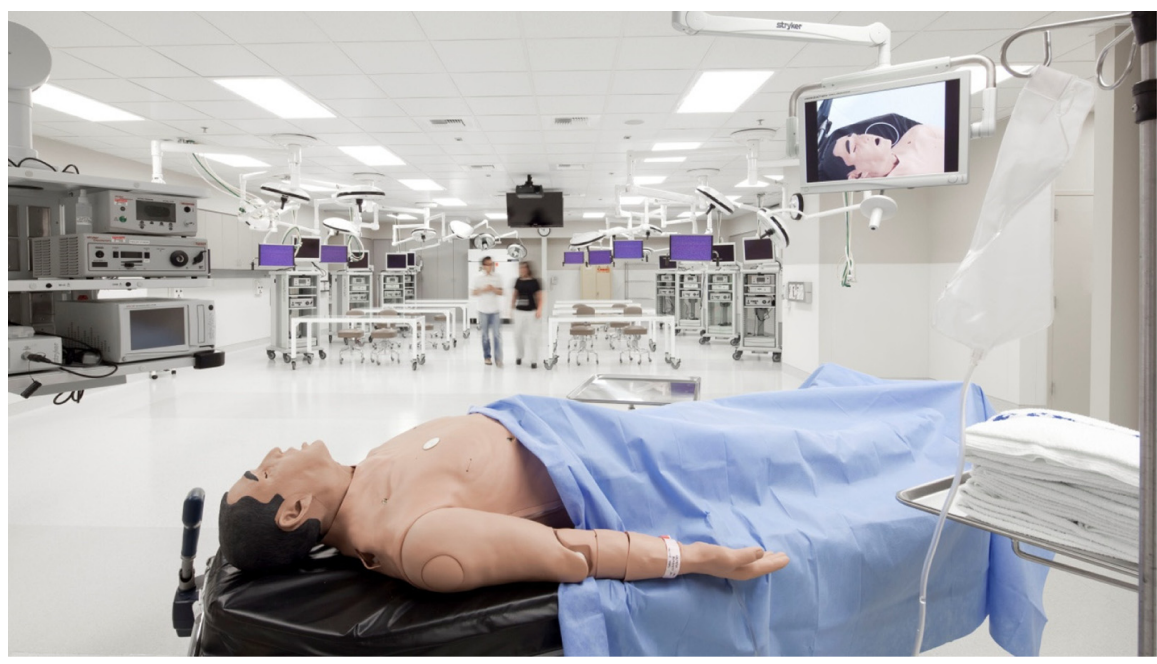

Figure 5 High fidelity mannequin in a state-of-the-art simulation facility.

Note: Courtesy of the University of Washington Institute for Simulation and Interprofessional Studies. 
and measure. Investigation into these findings continues, and poses a significant challenge to resources and study design. While it will likely be many years before we are able to determine the neurologic effects of sedation and anesthesia drugs with confidence, this is an area that providers must be familiar with. We do not definitively know the long-term effects of these drugs, so we must exercise judgment in recommending these services to pediatric patients. Parents should be informed of procedural risks and benefits, and sedation must only be employed when a significant benefit to the patient can be expected.

\section{Increasing sedation success}

A number of sedation rating scales have been used to evaluate sedation quality and child behavior. According to a recent review of the pediatric dental sedation literature, the Houpt Behavior Rating Scale (HBRS) has been used most frequently in research. ${ }^{81}$ The advantage of the HBRS is that it allows for evaluation of sedation depth, the child's behavior, and an overall rating of the visit (Table 1). One disadvantage of this rating system is that the measure of success focuses primarily on the clinician's ability to complete treatment. While clearly central to the HBRS, this characteristic is found in many other common sedation scales, including the Frankl, Ramsay, and Ohio State University Behavior Rating Scale. ${ }^{82-85}$ A number of authors have suggested that outcome assessment should be more patient-focused. This recognizes that the intent of sedation is not only to complete a procedure with minimal movement and crying, but also that the child leaves with a positive impression of dental care. ${ }^{81,86}$

When considering lighter sedation techniques, case selection becomes increasingly important. ${ }^{87}$ Child temperament or "behavioral style" is one factor associated with success in procedural sedation. Temperament has been defined as "[...] constitutional differences in reactivity and regulation [...] influenced over time by heredity, maturation, and experience". ${ }^{88}$ Since the 1950 s, a number of instruments have been used to evaluate child temperament. While measures vary in the literature, research has elucidated the type of child temperament associated with positive sedation outcomes. Characteristics such as emotionality, impulsivity, inflexibility, shyness, and difficulty dealing with new situations appear to be associated with sedation failure. ${ }^{89-91}$ Conversely, adaptability, persistence, and the ability to self-regulate may be associated with increased likelihood of success. ${ }^{92,93}$ Therefore, when considering a child for sedation, pay close attention to the behavior of the child during the consultation visit. Children who are shy, cling to parents, have difficulty tolerating simple tasks (such as dental prophylaxis or radiographs), and are unwilling to interact with the clinician may be better suited for alternative methods of behavior guidance, including general anesthesia or delayed treatment.

Children who receive mild to moderate sedation are expected to be awake and responsive to direction from the treating dentist. Therefore, it is imperative that clinicians employ their best non-pharmacologic behavior management skills with sedated patients. ${ }^{13}$ While these skills are generally regarded as a core competency of pediatric dentistry, they are increasingly being recognized as important in the medical literature as well. ${ }^{94-98}$ Interventions such as distraction have been shown to decrease anxiety and pain perception in non-sedated patients. ${ }^{99}$ When effectively incorporated into the sedation scheme, a combined pharmacologic and nonpharmacologic technique was also more effective at reducing child distress than pharmacologic techniques alone. ${ }^{100}$ Non-pharmacologic methods may be particularly effective for sedated young children with active imaginations. Also, because adequate sedation requires both anxiety reduction and pain control, excellent local anesthesia is critical. A child with profound analgesia is much more likely to be in a state of mind that facilitates good sedation.

\section{Increasing role of dental anesthesia}

Today's sedation practitioner faces significant challenges to achieve the described levels of child-centered care. Reports indicate that while child behavior in the dental office is

Table I Houpt Behavior Rating Scale

\begin{tabular}{|c|c|c|c|}
\hline Alertness & Crying & Movement & Overall \\
\hline Asleep & No crying & No movement & Excellent: no crying or movement \\
\hline Drowsy, disoriented & Intermittent or mild crying & $\begin{array}{l}\text { Controllable, not interfering with } \\
\text { treatment }\end{array}$ & Very good: some limited crying or movement \\
\hline \multirow[t]{5}{*}{ Fully awake, alert } & Continuous or strong crying & Continuous, making treatment difficult & Good: difficult, but all treatment was performed \\
\hline & Hysterical crying & Violent, interrupting movement & $\begin{array}{l}\text { Fair: treatment interrupted, but eventually } \\
\text { completed }\end{array}$ \\
\hline & & & Poor: treatment interrupted, only partial \\
\hline & & & treatment was completed \\
\hline & & & Aborted: no treatment rendered \\
\hline
\end{tabular}


becoming more difficult, parents are becoming increasingly particular about their child's experience. ${ }^{8,101,102}$ At the same time, concerns about child safety during sedation procedures have drawn scrutiny of sedation performed by dental practitioners in the office setting. The use of general anesthesia for pediatric dental treatment has grown accordingly. Surveys indicate that over the past 30 years parents have become much more accepting of general anesthesia for dental treatment. ${ }^{103}$ This may be due to the public's familiarity with anesthesia performed in surgery centers and other outpatient facilities. While in the past, nearly all dental surgery was provided in the hospital setting, today dentists are incorporating outpatient anesthesia services into their private offices. ${ }^{102,104}$ With the increased availability of ambulatory anesthesia services, general anesthesia in the dental clinic has become a safe and cost-effective mechanism to deliver dental care to healthy children. Consequently, it is possible that in the future we will see a trend toward lighter in-office sedation. In turn, for larger cases and more difficult patients, general anesthesia may replace deeper sedation techniques.

\section{Conclusion}

Providing quality dental care to young children can be a challenge. Pediatric dental sedation allows the clinician to provide treatment in a way that is minimally traumatic and preserves the child's trust. Although sedation is an effective tool to manage pediatric anxiety, adverse treatment outcomes and increased regulatory scrutiny have made this a contentious area. Therefore, practitioners should strive to reduce patient risk by carefully selecting patients who are medically optimized for sedation and instilling a culture of safety into clinical practice. Given parent preferences and high levels of pediatric dental disease, it is likely that we will see the need for sedation continue to grow in the future. This is an exciting opportunity to increase sedation success by refining behavioral selection parameters, utilizing modern drugs and routes, and employing the services of anesthesiologists in outpatient settings.

\section{Disclosure}

The authors report no conflicts of interest in this work.

\section{References}

1. Sheiham A. Dental caries affects body weight, growth and quality of life in pre-school. Br Dent J. 2006;201:625-626.

2. Berg J, Slayton R. Early Childhood Oral Health. 1st ed. Hoboken, NJ, USA: Wiley-Blackwell; 2009.

3. Edelstein B, Vargas C, Candelaria D, Vemuri M. Experience and policy implications of children presenting with dental emergencies to US pediatric dentistry training programs. Pediatr Dent. 2006;28:431-437.

4. Locker D, Liddell A, Dempster L, Shapiro D. Age of onset of dental anxiety. J Dent Res. 1999;78:790-796.
5. Milgrom P, Newton JT, Boyle C, Heaton LJ, Donaldson N. The effects of dental anxiety and irregular attendance on referral for dental treatment under sedation within the National Health Service in London. Community Dent Oral Epidemiol. 2010;38:453-459.

6. Milgrom P, Fiset L, Melnick S, Weinstein P. The prevalence and practice management consequences of dental fear in a major US city. J Am Dent Assoc. 1988;116:641-647.

7. Wilson S. Pharmacological management of the pediatric dental patient. Pediatr Dent. 2004;26:131-136.

8. Casamassimo PS, Wilson S, Gross L. Effects of changing US parenting styles on dental practice: perceptions of diplomates of the American Board of Pediatric Dentistry presented to the College of Diplomates of the American Board of Pediatric Dentistry 16th Annual Session, Atlanta, Ga, Saturday, May 26, 2001. Pediatr Dent. 2002;24:18-22.

9. Kaste LM, Drury TF, Horowitz AM, Beltran E. An evaluation of NHANES III estimates of early childhood caries. J Public Health Dent. 1999;59:198-200

10. Dye BA, Tan S, Smith V, et al. Trends in oral health status: United States, 1988-1994 and 1999-2004. Vital Health Stat 11. 2007;1:92.

11. Edelstein BL, Douglass CW. Dispelling the myth that 50 percent of US schoolchildren have never had a cavity. Public Health Rep. 1995;110: 522-530.

12. Wilkinson GR. Drug metabolism and variability among patients in drug response. N Engl J Med. 2005;352:2211-2221.

13. Nelson T, Nelson G. The role of sedation in contemporary pediatric dentistry. Dent Clin North Am. 2013;57:145-161.

14. Joint Commission on Accreditation of Healthcare Organizations. Revisions to anesthesia care standards. Comprehensive Accreditation Manual for Ambulatory Care, 2012. Available from http://www. google $. \operatorname{com} /$ url $? \mathrm{sa}=\mathrm{t} \& \mathrm{rct}=\mathrm{j} \& \mathrm{q}=\&$ esrc $=\mathrm{s} \&$ source $=$ web $\& \mathrm{~cd}=1 \&$ ved $=0 \mathrm{CB} 8 \mathrm{QFj} \mathrm{AA} \& \mathrm{url}=\mathrm{http} \% 3 \mathrm{~A} \% 2 \mathrm{~F} \% 2 \mathrm{Fwww}$.jointcommission. org\%2Fassets\%2F1\%2F18\%2F2011_ahc_hdbk.pdf\&ei=MyWgV Y3nPNb6oQSX85CQCw\&usg=AFQjCNFLGu_ST4go7xbcMEW 5IFXnwP3U_w\&sig2=JBHPPDxeRDJ0AomJjRNvRQ\&bvm=bv. 97653015, d.cGU.

15. Joint Commission on Accreditation of Healthcare Organizations. Comprehensive Accreditation Manual for Hospitals. Oakbrook, IL, USA: Joint Commission on Accreditation of Healthcare Organizations; 2000.

16. American Academy on Pediatrics; American Academy on Pediatric Dentistry. Guideline for monitoring and management of pediatric patients during and after sedation for diagnostic and therapeutic procedures. Pediatr Dent. 2008;30:143-159.

17. Cote CJ, Notterman DA, Karl HW, Weinberg JA, McCloskey C. Adverse sedation events in pediatrics: a critical incident analysis of contributing factors. Pediatrics. 2000;105:805-814.

18. Chicka MC, Dembo JB, Mathu-Muju KR, Nash DA, Bush HM. Adverse events during pediatric dental anesthesia and sedation: a review of. Pediatr Dent. 2012;34:231-238.

19. Costa LR, Costa PS, Brasileiro SV, Bendo CB, Viegas CM, Paiva SM. Post-discharge adverse events following pediatric sedation with high doses of oral medication. J Pediatr. 2012;160:807-813.

20. Cravero JP, Blike GT, Beach M, et al. Incidence and nature of adverse events during pediatric sedation/anesthesia for procedures outside the operating room: report from the Pediatric Sedation Research Consortium. Pediatrics. 2006;118:1087-1096.

21. Lee HH, Milgrom P, Starks H, Burke W. Trends in death associated with pediatric dental sedation and general anesthesia. Paediatr Anaesth. 2013;23:741-746.

22. Cravero JP, Blike GT. Pediatric anesthesia in the nonoperating room setting. Curr Opin Anaesthesiol. 2006;19:443-449.

23. Committee on Drugs. American Academy of Pediatrics. Guidelines for monitoring and management of pediatric patients during and after sedation for diagnostic and therapeutic procedures: addendum. Pediatrics. 2002;110:836-838.

24. [No authors listed]. American Academy of Pediatrics Committee on Drugs: Guidelines for monitoring and management of pediatric patients during and after sedation for diagnostic and therapeutic procedures. Pediatrics. 1992;89:1110-1115. 
25. Weaver J. The latest ASA mandate: $\mathrm{CO}(2)$ monitoring for moderate and deep sedation. Anesth Prog. 2011;58:111-112.

26. American Dental Association. Guidelines for the use of sedation and general anesthesia by dentists, 2012. Available from: http://www.ada.org/ media/ADA/About\%20the\%20ADA/Files/anesthesia_use_guidelines. ashx. Accessed June 19, 2015.

27. LaPointe L, Guelmann M, Primosch R. State regulations governing oral sedation in dental practice. Pediatr Dent. 2012;34:489-492.

28. Chopra R, Mittal M, Bansal K, Chaudhuri P. Buccal midazolam spray as an alternative to intranasal route for conscious sedation in pediatric dentistry. J Clin Pediatr Dent. 2013;38:171-173.

29. Primosch RE, Guelmann M. Comparison of drops versus spray administration of intranasal midazolam in two- and three-year-old children for dental sedation. Pediatr Dent. 2005;27:401-408.

30. Bahetwar SK, Pandey RK, Saksena AK, Chandra G. A comparative evaluation of intranasal midazolam, ketamine and their combination for sedation of young uncooperative pediatric dental patients: a triple blind randomized crossover trial. J Clin Pediatr Dent. 2011;35:415-420.

31. Primosch RE, Bender F. Factors associated with administration route when using midazolam for pediatric conscious sedation. ASDC J Dent Child. 2001;68:233-238.

32. Al-Rakaf H, Bello LL, Turkustani A, Adenubi JO. Intra-nasal midazolam in conscious sedation of young paediatric dental patients. Int $J$ Paediatr Dent. 2001;11:33-40.

33. Hartgraves PM, Primosch RE. An evaluation of oral and nasal midazolam for pediatric dental sedation. ASDC J Dent Child. 1994;61:175-181.

34. Fukuta O, Braham RL, Yanase H, Kurosu K. The sedative effects of intranasal midazolam administration in the dental treatment of patients with mental disabilities. Part 2: optimal concentration of intranasal midazolam. J Clin Pediatr Dent. 1994;18:259-265.

35. Fukuta O, Braham RL, Yanase H, Atsumi N, Kurosu K. The sedative effect of intranasal midazolam administration in the dental treatment of patients with mental disabilities. Part 1 . The effect of a $0.2 \mathrm{mg} / \mathrm{kg}$ dose. J Clin Pediatr Dent. 1993;17:231-237.

36. Fuks AB, Kaufman E, Ram D, Hovav S, Shapira J. Assessment of two doses of intranasal midazolam for sedation of young pediatric dental patients. Pediatr Dent. 1994;16:301-305.

37. Chopra R, Marwaha M. Assessment of buccal aerosolized midazolam for pediatric conscious sedation. J Investig Clin Dent. 2015;6: 40-44.

38. Schwagmeier R, Alincic S, Striebel HW. Midazolam pharmacokinetics following intravenous and buccal administration. Br J Clin Pharmacol. 1998;46:203-206.

39. Klein EJ, Brown JC, Kobayashi A, Osincup D, Seidel K. A randomized clinical trial comparing oral, aerosolized intranasal, and aerosolized buccal midazolam. Ann Emerg Med. 2011;58:323-329.

40. Tavassoli-Hojjati S, Mehran M, Haghgoo R, Tohid-Rahbari M, Ahmadi R. Comparison of oral and buccal midazolam for pediatric dental sedation: a randomized, cross-over, clinical trial for efficacy, acceptance and safety. Iran J Pediatr. 2014;24:198-206.

41. Sunbul N, Delvi MB, Zahrani TA, Salama F. Buccal versus intranasal midazolam sedation for pediatric dental patients. Pediatr Dent. 2014;36:483-488.

42. Mason KP. Sedation trends in the 21st century: the transition to dexmedetomidine for radiological imaging studies. Paediatr Anaesth. 2010;20:265-272.

43. McMorrow SP, Abramo TJ. Dexmedetomidine sedation: uses in pediatric procedural sedation outside the operating room. Pediatr Emerg Care. 2012;28:292-296.

44. Hitt JM, Corcoran T, Michienzi K, Creighton P, Heard C. An evaluation of intranasal sufentanil and dexmedetomidine for pediatric dental sedation. Pharmaceutics. 2014;6:175-184.

45. Cimen ZS, Hanci A, Sivrikaya GU, Kilinc LT, Erol MK. Comparison of buccal and nasal dexmedetomidine premedication for pediatric patients. Paediatr Anaesth. 2013;23:134-138.

46. Zub D, Berkenbosch JW, Tobias JD. Preliminary experience with oral dexmedetomidine for procedural and anesthetic premedication. Paediatr Anaesth. 2005;15:932-938.
47. Cooper JB, Newbower RS, Kitz RJ. An analysis of major errors and equipment failures in anesthesia management: considerations for prevention and detection. Anesthesiology. 1984;60:34-42.

48. Gaba DM. Human error in anesthetic mishaps. Int Anesthesiol Clin. 1989;27:137-147.

49. Hoffman GM, Nowakowski R, Troshynski TJ, Berens RJ, Weisman SJ. Risk reduction in pediatric procedural sedation by application of an American Academy of Pediatrics/American Society of Anesthesiologists process model. Pediatrics. 2002;109:236-243.

50. Mason KP, Green SM, Piacevoli Q. Adverse event reporting tool to standardize the reporting and tracking of adverse events during procedural sedation: a consensus document from the World SIVA International Sedation Task Force. Br J Anaesth. 2012;108:13-20.

51. Shannon M, Albers G, Burkhart K, et al. Safety and efficacy of flumazenil in the reversal of benzodiazepine-induced conscious sedation. The Flumazenil Pediatric Study Group. J Pediatr. 1997;131: $582-586$.

52. Ramaiah R, Bhananker S. Pediatric procedural sedation and analgesia outside the operating room: anticipating, avoiding and managing complications. Expert Rev Neurother. 2011;11:755-763.

53. Grunwell JR, McCracken C, Fortenberry J, Stockwell J, Kamat P. Risk factors leading to failed procedural sedation in children outside the operating room. Pediatr Emerg Care. 2014;30:381-387.

54. Ogden CL, Carroll MD, Kit BK, Flegal KM. Prevalence of obesity and trends in body mass index among US children and adolescents, 1999-2010. JAMA. 2012;307:483-490.

55. Nafiu OO, Reynolds PI, Bamgbade OA, Tremper KK, Welch K, Kasa-Vubu JZ. Childhood body mass index and perioperative complications. Paediatr Anaesth. 2007;17:426-430.

56. Tan HL, Gozal D, Kheirandish-Gozal L. Obstructive sleep apnea in children: a critical update. Nat Sci Sleep. 2013;5:109-123.

57. Kendrick JG, Carr RR, Ensom MH. Pharmacokinetics and drug dosing in obese children. J Pediatr Pharmacol Ther. 2010;15:94-109.

58. Ingrande J, Brodsky JB, Lemmens HJ. Lean body weight scalar for the anesthetic induction dose of propofol in morbidly obese subjects. Anesth Analg. 2011;113:57-62.

59. Ingrande J, Lemmens HJ. Dose adjustment of anaesthetics in the morbidly obese. Br J Anaesth. 2010;105 Suppl 1:i16-i23.

60. Callaghan LC, Walker JD. An aid to drug dosing safety in obese children: development of a new nomogram and comparison with existing methods for estimation of ideal body weight and lean body mass. Anaesthesia. 2015;70:176-182.

61. Martinez D, Wilson S. Children sedated for dental care: a pilot study of the 24-hour postsedation period. Pediatr Dent. 2006;28:260-264.

62. Dosani FZ, Flaitz CM, Whitmire HC Jr, Vance BJ, Hill JR. Postdischarge events occurring after pediatric sedation for dentistry. Pediatr Dent. 2014;36:411-416.

63. Cote CJ. Discharge criteria for children sedated by nonanesthesiologists: is "safe" really safe enough? Anesthesiology. 2004;100: 207-209.

64. Malviya S, Voepel-Lewis T, Ludomirsky A, Marshall J, Tait AR. Can we improve the assessment of discharge readiness?: a comparative study of observational and objective measures of depth of sedation in children. Anesthesiology. 2004;100:218-224.

65. Tobin CD, Clark CA, McEvoy MD, et al. An approach to moderate sedation simulation training. Simul Healthc. 2013;8:114-123.

66. Tan GM. A medical crisis management simulation activity for pediatric dental residents and assistants. J Dent Educ. 2011;75:782-790.

67. Shavit I, Keidan I, Hoffmann Y, et al. Enhancing patient safety during pediatric sedation: the impact of simulation-based training of nonanesthesiologists. Arch Pediatr Adolesc Med. 2007;161:740-743.

68. Stratmann G. Review article: Neurotoxicity of anesthetic drugs in the developing brain. Anesth Analg. 2011;113:1170-1179.

69. Sun L. Early childhood general anaesthesia exposure and neurocognitive development. Br J Anaesth. 2010;105 Suppl 1:i61-i68.

70. Loepke AW, Soriano SG. An assessment of the effects of general anesthetics on developing brain structure and neurocognitive function. Anesth Analg. 2008;106:1681-1707. 
71. Jevtovic-Todorovic V, Hartman RE, Izumi Y, et al. Early exposure to common anesthetic agents causes widespread neurodegeneration in the developing rat brain and persistent learning deficits. $J$ Neurosci. 2003;23:876-882.

72. Slikker W Jr, Zou X, Hotchkiss CE, et al. Ketamine-induced neuronal cell death in the perinatal rhesus monkey. Toxicol Sci. 2007;98: $145-158$.

73. Creeley C, Dikranian K, Dissen G, Martin L, Olney J, Brambrink A. Propofol-induced apoptosis of neurones and oligodendrocytes in fetal and neonatal rhesus macaque brain. Br J Anaesth. 2013;110 Suppl 1: i29-i38.

74. Brambrink AM, Evers AS, Avidan MS, et al. Isoflurane-induced neuroapoptosis in the neonatal rhesus macaque brain. Anesthesiology. 2010;112:834-841.

75. Sun LS, Li G, Dimaggio C, et al. Anesthesia and neurodevelopment in children: time for an answer? Anesthesiology. 2008;109:757-761.

76. DiMaggio C, Sun LS, Kakavouli A, Byrne MW, Li G. A retrospective cohort study of the association of anesthesia and hernia repair surgery with behavioral and developmental disorders in young children. J Neurosurg Anesthesiol. 2009;21:286-291.

77. DiMaggio C, Sun LS, Li G. Early childhood exposure to anesthesia and risk of developmental and behavioral disorders in a sibling birth cohort. Anesth Analg. 2011;113:1143-1151.

78. Flick RP, Katusic SK, Colligan RC, et al. Cognitive and behavioral outcomes after early exposure to anesthesia and surgery. Pediatrics. 2011;128:e1053-e1061.

79. Sprung J, Flick RP, Katusic SK, et al. Attention-deficit/hyperactivity disorder after early exposure to procedures requiring general anesthesia. Mayo Clin Proc. 2012;87:120-129.

80. Jevtovic-Todorovic V. Pediatric anesthesia neurotoxicity: an overview of the 2011 SmartTots panel. Anesth Analg. 2011;113:965-968.

81. Lourenco-Matharu L, Ashley PF, Furness S. Sedation of children undergoing dental treatment. Cochrane Database Syst Rev. 2012;3:CD003877.

82. Lochary ME, Wilson S, Griffen AL, Coury DL. Temperament as a predictor of behavior for conscious sedation in dentistry. Pediatr Dent. 1993; 15:348-352.

83. Frank1 S, Shiere F, Fogels H. Should the parent remain with the child in the dental operatory? J Dent Child. 1962;29:150-163.

84. Isik B, Baygin O, Kapci EG, Bodur H. The effects of temperament and behaviour problems on sedation failure in anxious children after midazolam premedication. Eur J Anaesthesiol. 2010;27:336-340.

85. Wan K, Jing Q, Zhao JZ. Evaluation of oral midazolam as conscious sedation for pediatric patients in oral restoration. Chin Med Sci J. 2006;21:163-166.

86. Vargas KG, Nathan JE, Qian F, Kupietzky A. Use of restraint and management style as parameters for defining sedation success: a survey of pediatric dentists. Pediatr Dent. 2007;29:220-227.

87. Radis FG, Wilson S, Griffen AL, Coury DL. Temperament as a predictor of behavior during initial dental examination in children. Pediatr Dent. 1994;16:121-127.

88. Rothbart MK, Ahadi SA, Evans DE. Temperament and personality: origins and outcomes. J Pers Soc Psychol. 2000;78:122-135.
89. Kain ZN, Caldwell-Andrews AA, Maranets I, Nelson W, Mayes LC. Predicting which child-parent pair will benefit from parental presence during. Anesth Analg. 2006;102:81-84.

90. Jensen B, Stjernqvist K. Temperament and acceptance of dental treatment under sedation in preschool children. Acta Odontol Scand. 2002;60:231-236.

91. Quinonez R, Santos RG, Boyar R, Cross H. Temperament and trait anxiety as predictors of child behavior prior to general anesthesia for dental surgery. Pediatr Dent. 1997;19:427-431.

92. Voepel-Lewis T, Malviya S, Prochaska G, Tait AR. Sedation failures in children undergoing MRI and CT: is temperament a factor? Paediatr Anaesth. 2000;10:319-323.

93. Salmon K, Pereira JK. Predicting children's response to an invasive medical investigation: the Influence of effortful control and parent behavior. J Pediatr Psychol. 2002;27:227-233.

94. McMurtry CM, Chambers CT, McGrath PJ, Asp E. When “don't worry" communicates fear: Children's perceptions of parental reassurance and distraction during a painful medical procedure. Pain. 2010;150:52-58.

95. McMurtry CM, McGrath PJ, Asp E, Chambers CT. Parental reassurance and pediatric procedural pain: a linguistic description. J Pain. 2007;8:95-101.

96. Chambers CT, Taddio A, Uman LS, McMurtry CM. Psychological interventions for reducing pain and distress during routine childhood immunizations: a systematic review. Clin Ther. 2009;31 Suppl 2: S77-S103.

97. Blount RL, Devine KA, Cheng PS, Simons LE, Hayutin L. The impact of adult behaviors and vocalizations on infant distress during immunizations. J Pediatr Psychol. 2008;33:1163-1174.

98. Blount RL, Landolf-Fritsche B, Powers SW, Sturges JW. Differences between high and low coping children and between parent and staff behaviors during painful medical procedures. J Pediatr Psychol. 1991; 16:795-809.

99. Sinha M, Christopher NC, Fenn R, Reeves L. Evaluation of nonpharmacologic methods of pain and anxiety management for laceration repair in the pediatric emergency department. Pediatrics. 2006;117: 1162-1168.

100. Kazak AE, Penati B, Brophy P, Himelstein B. Pharmacologic and psychologic interventions for procedural pain. Pediatrics. 1998; 102:59-66.

101. Wilson S, Nathan JE. A survey study of sedation training in advanced pediatric dentistry programs: thoughts of program directors and students. Pediatr Dent. 2011;33:353-360.

102. Adair S, Waller J, Schafer T, Rockman R. A survey of members of the american academyof pediatric dentistry on their use of behavior management techniques. Pediatr Dent. 2004;2:159-166.

103. Eaton JJ, McTigue DJ, Fields HW Jr, Beck M. Attitudes of contemporary parents toward behavior management techniques used in. Pediatr Dent. 2005;27:107-113.

104. Olabi NF, Jones JE, Saxen MA, et al. The use of office-based sedation and general anesthesia by board certified. Anesth Prog. 2012;59: $12-17$
Clinical, Cosmetic and Investigational Dentistry

\section{Publish your work in this journal}

Clinical, Cosmetic and Investigational Dentistry is an international, peer-reviewed, open access, online journal focusing on the latest clinical and experimental research in dentistry with specific emphasis on cosmetic interventions. Innovative developments in dental materials, techniques and devices that improve outcomes and patient satisfac-

\section{Dovepress}

tion and preference will be highlighted. The manuscript management system is completely online and includes a very quick and fair peerreview system, which is all easy to use. Visit http://www.dovepress. com/testimonials.php to read real quotes from published authors. 